\title{
Una relación compleja: Estrés psicosocial, contaminación y salud*
}

E n años recientes un número cada vez mayor de estudios han demostrado que el estrés psicosocial puede exacerbar la susceptibilidad a los efectos adversos de contaminantes tales como el plomo, los bifenilos policlorados y las emisiones resultantes de la combustión. Para medir y evaluar con exactitud los efectos del estrés sobre la susceptibilidad de la gente a los contaminantes, los investigadores necesitan basarse en las herramientas y hallazgos de la epidemiología social y de la ciencia de la salud ambiental, según una reseña sobre las investigaciones realizadas hasta la fecha [EHP 117:1351-1358; Clougherty and Kubzansky]. Los autores ofrecen recomendaciones específicas sobre el modo en que los investigadores pueden combinar técnicas tomadas de estos campos para investigar los vínculos entre el estrés, la contaminación y la salud.

En estudios anteriores realizados por los propios autores éstos encontraron que al parecer el estrés exacerbaba los efectos de la contaminación, lo cual sugiere que el estrés incrementa la susceptibilidad a las exposiciones ambientales. Sin embargo, también observaron que la interacción entre el estrés y la contaminación dejaba de ser evidente más allá de cierto rango de exposición, fenómeno al que se refieren como efecto de saturación. Por ejemplo: si los niveles de contaminación atmosférica son muy elevados, el estrés puede no tener ningún efecto adicional sobre la probabilidad de que se presenten síntomas de asma, y viceversa.

Asimismo es importante prestar atención a las diferencias en los patrones espaciales de las exposiciones sociales y físicas. A manera de ejemplo, los autores escriben: "los epidemiólogos espaciales enfrentan el reto de diferenciar los efectos de la contaminación relacionada con el tráfico vehicular sobre la salud de los efectos de otros factores espacialmente correlacionados como el ruido, el estrés o la pobreza." Puede resultar particularmente difícil separar los efectos de diferentes exposiciones cuando tienen las mismas consecuencias para la salud. Es más, no necesariamente todos los individuos de este barrio muestra experimentan niveles elevados de estrés, ni todos los individuos reciben las mismas exposiciones a la contaminación relacionada con el tráfico vehicular, las cuales, señalan los autores, varían drásticamente dentro de una distancia de 50 a 200 metros de las principales vías de circulación.

Para comprender los efectos combinados del estrés y la exposición a los contaminantes, el tiempo lo es todo porque el estrés agudo y el crónico pueden producir resultados diferentes. El estrés agudo puede producir respuestas de "luchar o huir" que podrían servir de contrapeso a los efectos de la contaminación; por ejemplo: la broncodilatación inducida por el estrés podría reducir o enmascarar temporalmente una constricción bronquial provocada por la contaminación atmosférica. El estrés crónico tiende más a debilitar gradualmente el sistema inmune, incrementando la susceptibilidad a las enfermedades relacionadas con la contaminación. Además, el estrés es multidimensional; incluye el estímulo que plantea el reto, la evaluación del factor estresante por la persona y, por último, la respuesta psicológica y fisiológica.

$\mathrm{Al}$ medir el estrés, los investigadores deben tomar en cuenta qué etapa de la experiencia de estrés están observando. Deben además rastrear el momento relativo de las exposiciones de los participantes en el estudio a fin de determinar si el estrés ocurrió antes, durante o después de la exposición al contaminante. Resumiendo, los autores escriben: "Estos temas son excesivamente complicados, y el caracterizar de manera exacta las exposiciones tanto sociales como físicas representa un reto considerable, es una tarea que debe ejecutarse con cuidado... antes de analizar e interpretar las interacciones."

Tina Adler fue la primera en escribir para EHP sobre la agenda ambiental de Clinton y Gore en 1993. Es miembro de la Asociación Nacional de Escritores Cientificos y de la Sociedad Americana de Periodistas y Autores.

* Publicado originalmente en Environmental Health Perspectives, volumen 117, número 9, septiembre 2009, página A407. 